\title{
Visual Outcome in Patients with Acute Invasive Fungal Rhinosinusitis
}

\author{
${ }^{1}$ Anuragini Gupta, ${ }^{2}$ PK Rathore, ${ }^{3}$ Vikas Malhotra
}

\begin{abstract}
Acute invasive fungal rhinosinusitis (AIFRS) is an aggressive disease with fatal complications. The mortality rate of AIFRS ranges between 49 and $62 \%$. The incidence of visual loss in AIFRS has been reported to be between 26 and $29 \%$. A total of 5/16 patients in our study showed improvement in vision after treatment in 1 year follow-up while 11 patients showed no improvement in visual acuity. The AIFRS with visual loss is managed using systemic amphotericin B with a combination of surgical debridement.
\end{abstract}

Keywords: Acute invasive fungal rhinosinusitis, Fungal rhinosinusitis, Invasive aspergillosis, Rhino-orbital aspergillosis

How to cite this article: Gupta A, Rathore PK, Malhotra V. Visual Outcome in Patients with Acute Invasive Fungal Rhinosinusitis. Clin Rhinol An Int J 2017;10(3):120-123.

\section{Source of support: Nil}

Conflict of interest: None

\section{INTRODUCTION}

Acute invasive fungal rhinosinusitis is a potentially fulminant disease that primarily occurs in immunocompromised patients.

It most commonly occurs in individuals with hematological malignancies ${ }^{1,2}$ chronic steroid use, poorly controlled diabetes, human immunodeficiency virus (HIV)-positive patients, and patients on chemoradiation therapy ${ }^{3-5}$ Most common organisms causing AIFRS are Mucor and Aspergillus. ${ }^{4,6,7}$ Histological features to diagnose AIFRS include fungi breaching mucosal barrier and tissue necrosis. The fungus invades blood vessels generating angiocentric necrosis. ${ }^{8,9}$ The clinical manifestations are often nonspecific and diverse including fever, nasal obstruction, and rhinorrhea. More concerning symptoms, such as visual loss, facial paresthesia, and cranial neuropathy, however, may occur. The survival rates of patients with AIFRS are varied, ranging from 20 to $80 \% .{ }^{1-4}$ There

\footnotetext{
${ }^{1}$ Senior Resident, ${ }^{2}$ Professor and Head, ${ }^{3}$ Professor

${ }^{1-3}$ Department of Otorhinolaryngology (ENT), Maulana Azad Medical College, New Delhi, India
}

Corresponding Author: Anuragini Gupta, Senior Resident Department of Otorhinolaryngology (ENT), Maulana Azad Medical College, New Delhi, India, e-mail: anuragini25@ hotmail.com is dearth of studies in the literature focusing on outcome of patients with visual loss following AIFRS. We hereby present our study of 16 patients with AIFRS with visual loss and their functional outcome at 1-year follow-up.

\section{MATERIALS AND METHODS}

This is a prospective study on 33 diagnosed cases of AIFRS with vision loss conducted in the Department of ENT at Lok Nayak Hospital and Maulana Azad Medical College, New Delhi, India. The study was conducted from December 2015 to May 2017. Inclusion criterion was patients with acute vision loss following AIFRS. Patients not willing to be part of the study were excluded from the study. Ethical clearance was obtained from the local institutional ethical committee.

A total of 33 consecutive patients suffering from vision loss due to AIFRS were included in the study after taking informed written consent. The diagnosis was established by obtaining endoscopic nasal biopsies. The treatment included surgical debridement with medical management using systemic antifungal drugs. Functional outcome of visual loss was assessed by conducting visual acuity testing and fundoscopy at 3 weeks, 3 months, 6 months, and 1 year. Nasal endoscopy was also carried out to evaluate status of nasal mucosa

A contrast-enhanced magnetic resonance imaging (MRI) shows necrosis of mucosa in nose and paranasal sinuses with nonenhancing angioinvasion of fungal infection. A total of 12 of 33 patients had rhinocerebral involvement with areas of diffuse involvement with infarcts in cerebral hemisphere (Fig. 1). Four patients had associated leptomeningeal enhancement indicating meningitis. A total of 16 of 33 patients had rhino-orbital manifestation in the form of involvement of glow, orbital apex involvement (Fig. 2), and cavernous sinus involvement (Figs 3 and 4). A total of 5 of 33 patients had rhinoorbito-cerebral involvement.

\section{SURGICAL TECHNIQUE}

All patients underwent radical surgical debridement of disease and affected nasal mucosa with wide margins (parts of middle turbinate, nasal septum, and nasal floor) until vascularized tissue was encountered (Fig. 5). Surgical debridement focused on reducing fungal load and 


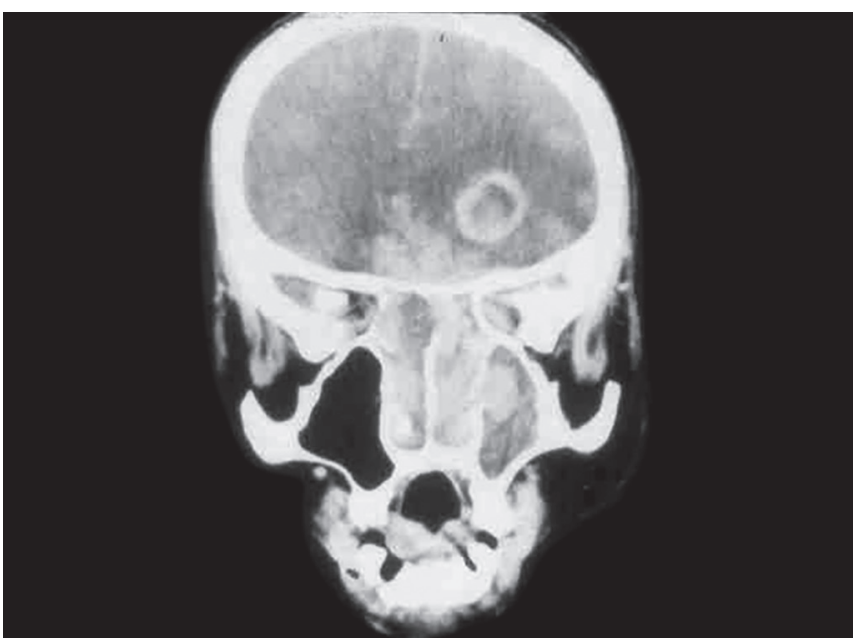

Fig. 1: Contrast-enhanced MRI showing involvement of frontal lobe

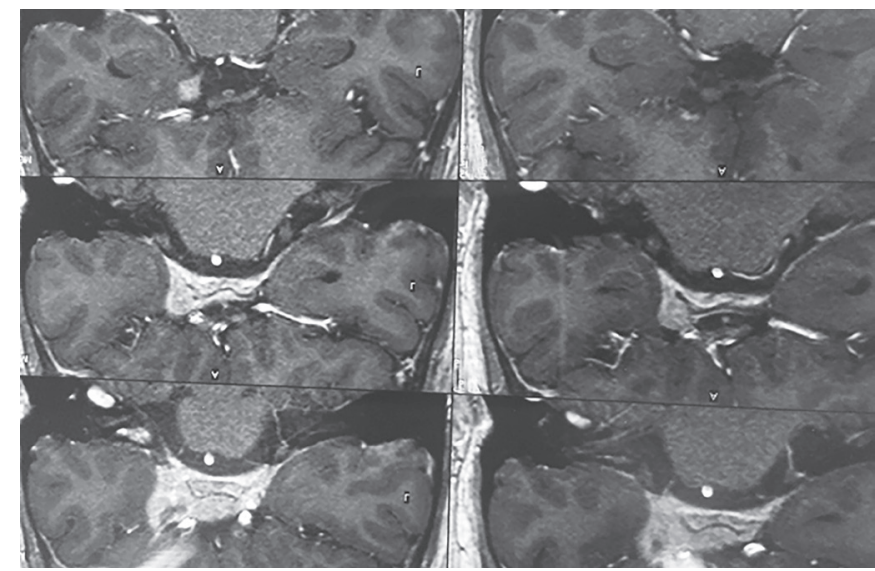

Fig. 3: MRI showing cavernous sinus involvement
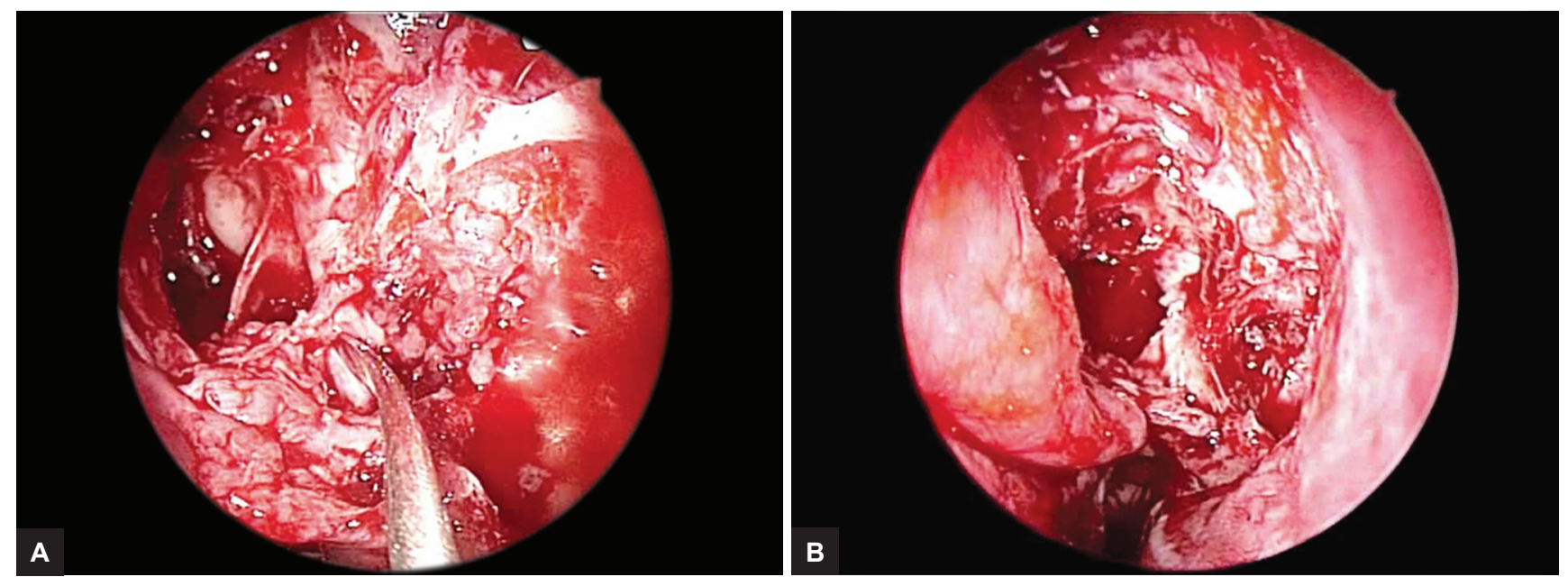

Figs 5A and B: Peroperative photographs showing debridement of diseased mucosa

better penetration of antifungal medication. ${ }^{10}$ Antifungal medication amphotericin B $(3-7 \mathrm{mg} / \mathrm{kg})$ was started in all patients of mucormycosis. Itraconazole $200 \mathrm{mg}$ bd combined with amphotericin B was started for Aspergillus fungus species. Baseline investigations including renal

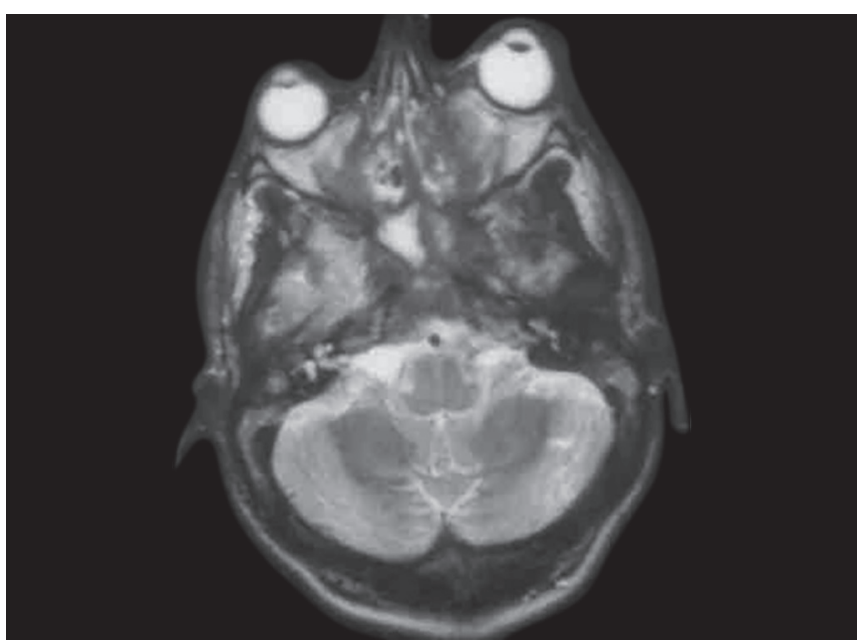

Fig. 2: Contrast-enhanced MRI showing orbital apex involvement

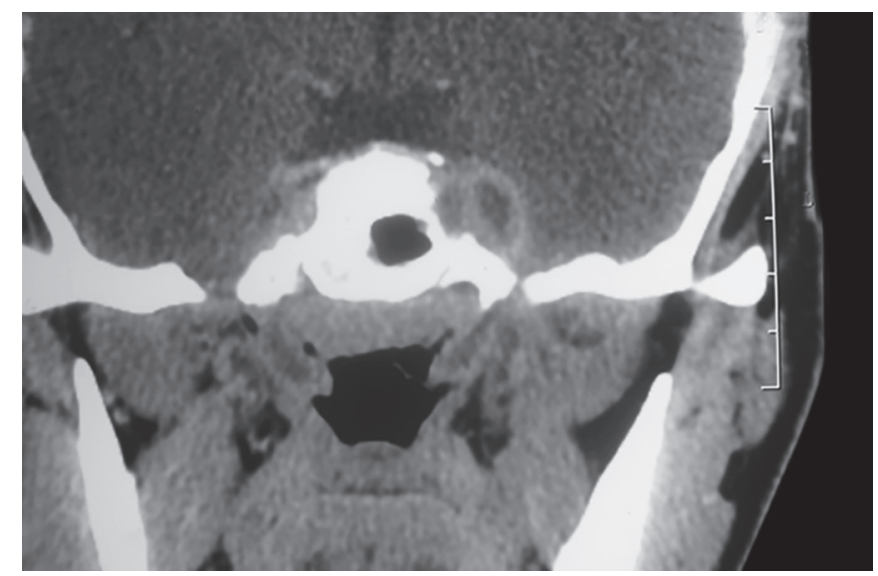

Fig. 4: MRI showing hypointense shadow in the area of cavernous sinus 


\section{RESULTS}

Out of 33 patients, 5 patients were lost to follow-up; 12 patients died due to complications of underlying disorder (leukemia and uncontrolled diabetes).

Of the 21 patients, 12 were males and 6 were females. The mean of the patients was 58 years ( $16-81$ years). A total of 12 of 33 patients expired within 1 year of being diagnosed with AIFRS (mortality rate of $36.36 \%$ ); 8 of 12 patients suffered from uncontrolled diabetes, 3 of 12 suffered from hematological malignancies, and 1 was suffering from HIV/acquired immunodeficiency syndrome. The cause of death in these patients was recurrent infections due to their immunocompromised status. Five patients were lost to follow-up.

Biopsy demonstrated mucormycosis in 28 of 33 patients and 5 of 33 demonstrated Mucor and Aspergillus species. Average number of debridement per patient was $2.8(2-4)$.

Of the 16 patients that were included in the study, 14 had unilateral vision loss and 2 patients had bilateral vision loss; both of these patients had visual loss as negative perception of light and atrophic changes on fundus examination. Of the remaining 14 patients with unilateral vision loss, 8 had negative perception of light with compromised vision in the other eye with absent fundus glow. Three patients had finger counting at $2 \mathrm{mg}$ and 3 had finger counting at $3 \mathrm{mg}$. The fundus examination showed evidence of papilledema.

On serial follow-up of these patients, 5 patients showed improvement and 11 did not show any improvement in visual acuity.

A postoperative computerized tomography was done at the end of 3 months to check for residual diseases (Fig. 6).

Out of five patients who had no perception of light at the time of presentation, three had positive perception of light at 6 weeks and two had perception of light positive

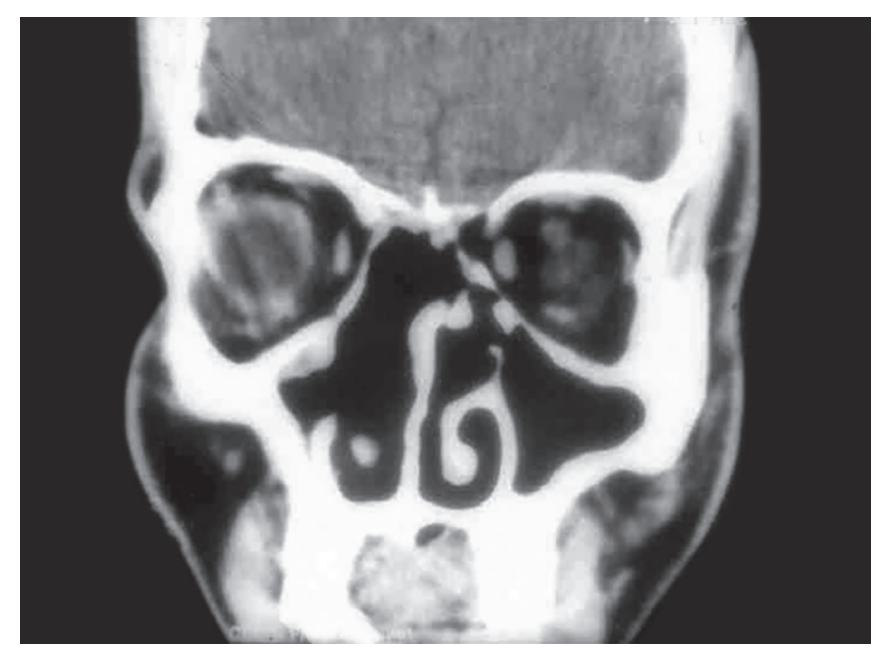

Fig. 6: CT scan showing postoperative cavity at 3 months follow-up. One of the three patients showed further improvement of vision to finger counting at $2 \mathrm{mg}$ at 3 months follow-up. The visual acuity remained the same till 1 year follow-up. Other two patients did not improve further beyond positive perception of light up to 1 year follow-up. The fundus examination revealed resolution of papilledema.

Two patients who showed improvement at 3 months follow-up did not show further improvement on subsequent follow-up visits.

\section{DISCUSSION}

The AIFRS is an aggressive disease with fatal complications. Fungal sinusitis is classified in two broad categories, namely (a) invasive and (b) noninvasive sinusitis. Invasive fungal sinusitis is further categorized as (1) acute invasive and (2) chronic invasive sinusitis (granulomatous and nongranulomatous). Noninvasive sinusitis has two forms: (1) Fungal ball and (2) allergic fungal sinusitis. The invasive nature of fungus is determined by the unique property of its hyphae to invade sinus mucosa, submucosa, sinus bony wall, orbit, and brain via angioinvasion. ${ }^{8}$ McGill in 1980 was the first to describe the acute invasive form of the disease. ${ }^{11}$ Time duration of 4 weeks is used to differentiate between acute and chronic forms of invasive fungal sinusitis. ${ }^{12}$ Majority of hosts suffering from AIFRS are immunocompromised. Vision loss is one of the most common and dreaded manifestations of AIFRS. ${ }^{\text {? }}$

The mortality rate of AIFRS ranges between 49 and $62 \%{ }^{10,13}$ The incidence of visual loss in AIFRS has been reported between 26 and $29 \%$. ${ }^{74}$

The mortality rate in our study was $40 \%(12 / 30)$, which is consistent with the English literature. Visual loss associated with AIFRS has poorer survival rate vis-à-vis AIFRS with visual loss. ${ }^{15}$ There is no study in the literature that follows outcomes of visual loss with AIFRS in terms of improvement of visual acuity on serial monitoring. A total of 5 of 16 patients in our study showed improvement in vision after treatment in 1 year followup, while 11 patients showed no improvement in visual acuity. The AIFRS with visual loss is managed using systemic amphotericin B with a combination of surgical debridement. ${ }^{16-18}$

Despite tremendous improvement in the management of AIFRS, this disease still has high mortality rate. Majority of patients who are able to survive the disease suffer from high morbidity associated with underlying disorders. Early identification and awareness among physicians, otorhinolaryngologists, ophthalmologists, critical care physicians, and neurosurgeons is needed to evade the wrath of this disease. Hence, a multidisciplinary approach is a must for better outcome. 


\section{REFERENCES}

1. Chen C-Y, Sheng W-H, Cheng A, Chen YC, Tsay W, Tang JL, Huang SY, Chang SC, Tien HF. Invasive fungal sinusitis in patients with hematological malignancy: 15 years experience in a single university hospital in Taiwan. BMC Infect Dis 2011 Sep;11:250.

2. Drakos PE, Nagler A, Or R, Naparstek E, Kapelushnik J, Engelhard D, Rahav G, Ne'emean D, Slavin S. Invasive fungal sinusitis in patients undergoing bone marrow transplantation. Bone Marrow Transplant 1993 Sep;12(3):203-208.

3. Parikh SL, Venkatraman G, DelGaudio JM. Invasive fungal sinusitis: a 15-year review from a single institution. Am J Rhinol 2004 Mar-Apr;18(2):75-81.

4. Monroe MM, McLean M, Sautter N, Wax MK, Andersen PE, Smith TL, Gross ND. Invasive fungal rhinosinusitis: a 15-year experience with 29 patients. Laryngoscope 2013 Jul;123(7):1583-1587.

5. DelGaudio JM, Clemson LA. An early detection protocol for invasive fungal sinusitis in neutropenic patients successfully reduces extent of disease at presentation and long term morbidity. Laryngoscope 2009 Jan;119(1):180-183.

6. Valera FCP, do Lago T, Tamashiro E, Yassuda CC, Silveira F, Anselmo-Lima WT. Prognosis of acute invasive fungal rhinosinusitis related to underlying disease. Int J Infect Dis 2011 Dec;15(12):e841-e844.

7. Cho H-J, Jang M-S, Hong SD, Chung S-K, Kim HY, DhongHJ. Prognostic factors for survival in patients with acute invasive fungal rhinosinusitis. Am J Rhinol Allergy 2015 Jan-Feb;29(1):48-53.

8. deShazo RD, O'Brien M, Chapin K, Soto-Aguilar M, Gardner L, Swain R. A new classification and diagnostic criteria for invasive fungal sinusitis. Arch Otolaryngol Head Neck Surg 1997 Nov;123(11):1181-1188.

9. Chakrabarti A, Denning DW, Ferguson BJ, Ponikau J, Buzina W, Kita H, Marple B, Panda N, VlaminckS, Kauffmann-Lacroix C, et al. Fungal rhinosinusitis: a categorization and definitional schema addressing current controversies. Laryngoscope 2009 Sep;119(9):1809-1818.

10. Siddiqui AA, Shah AA, Bashir SH. Craniocerebral aspergillosis of sinonasal origin in immunocompetent patients: clinical spectrum and outcome in 25 cases. Neurosurgery 2004 Sep;55(3):602-611; discussion 611-3.

11. McGill TJ, Simpson G, Healy GB. Fulminant aspergillosis of the nose and paranasal sinuses: a new clinical entity. Laryngoscope 1980 May;90(5 Pt 1):748-754.

12. Ferguson BJ. Definitions of fungal rhinosinusitis. Otolaryngol Clin North Am 2000 Apr;33(2):227-235.

13. Lin SJ, Schranz J, Teutsch SM. Aspergillosis case-fatality rate: systematic review of the literature. Clin Infect Dis 2001 Feb;32(3):358-366. Epub 2001 Jan 26.

14. Payne SJ, Mitzner R, Kunchala S, Roland L, McGinn JD. Acute invasive fungal rhinosinusitis: a 15-year experience with 41 patients. Otolaryngol Head Neck Surg 2016 Apr;154(4): 759-764. Epub 2016 Feb 16.

15. Bhansali A, Bhadada S, Sharma A, Suresh V, Gupta A, Singh P, Chakarbarti A, Dash RJ. Presentation and outcome of rhinoorbital-cerebral mucormycosis in patients with diabetes. Post Graduate Med J 2004 Nov;80(949):670-674.

16. Boelaert JR. Mucormycosis (zygomycosis): is there news for the clinician. J Infect 1994 May;28(Suppl 1):1-6.

17. Sugar AM. Mucormycosis. Clin Infect 1992;14:126-129.

18. Avet PP, Kline LB, Sillers MJ. Endoscopic sinus surgery in the management of mucormycosis. J Neuroophthalmol 1999 Mar;19(1):56-61. 